\title{
Reduction of tumor angiogenesis induced by desmopressin in a breast cancer model
}

\author{
Giselle V. Ripoll $\cdot$ Juan Garona $\cdot$ Marina Pifano \\ Hernan G. Farina • Daniel E. Gomez • \\ Daniel F. Alonso
}

Received: 8 August 2013/ Accepted: 3 October 2013/Published online: 12 October 2013

(C) The Author(s) 2013. This article is published with open access at Springerlink.com

\begin{abstract}
Desmopressin (DDAVP), a synthetic peptide analog of vasopressin, is a safe antidiuretic and hemostatic compound that acts as a selective agonist for the vasopressin V2 membrane receptor. It is known that DDAVP can inhibit progression of residual metastatic cells and also improves chemotherapy effects in preclinical breast cancer models. Here, we explored the effects of DDAVP on tumor angiogenesis using the aggressive F3II mammary carcinoma in syngeneic Balb/c mice. Intravenous administration of the compound $(2 \mu \mathrm{g} / \mathrm{kg})$ markedly decreased vascularization of growing subcutaneous tumors, as well as inhibited the early angiogenic response around intradermal inoculation sites. In vitro studies confirmed the presence of vasopressin V2 receptors on F3II cells and a modest antiproliferative activity of DDAVP. Interestingly, conditioned media from F3II monolayers exposed to low doses of DDAVP (100 nM) significantly increased angiostatin formation in the presence of purified plasminogen. Such increase was associated with an enhancement of tumorsecreted urokinase-type plasminogen activator, suggesting the proteolytic conversion of plasminogen to angiostatin in vitro. Similar results were observed with the MCF-7 human breast carcinoma, a cell line known to express the vasopressin V2 receptor. No direct effects of DDAVP $(100 \mathrm{nM}-1 \mu \mathrm{M})$ were found on capillary-like tube formation by human microvascular cells HMVEC. Our studies showed that DDAVP induces anti-angiogenic effects that may be associated with the generation of angiostatin by
\end{abstract}

G. V. Ripoll · J. Garona · M. Pifano · H. G. Farina ·

D. E. Gomez · D. F. Alonso ( $\square)$

Laboratorio de Oncología Molecular, Universidad Nacional de Quilmes, R. Sáenz Peña 352, Bernal, B1876BXD Buenos Aires, Argentina

e-mail: dfalonso@unq.edu.ar tumor cells. Further preclinical studies with DDAVP and other vasopressin analogs are warranted to determine their potential in cancer management.

Keywords Tumor vascularization · Vasopressin . Peptide analog $\cdot$ Angiostatin $\cdot$ Mammary carcinoma Mice

\section{Introduction}

Desmopressin (1-deamino-8-D-arginine vasopressin, DDAVP) is a synthetic analog of the antidiuretic hormone vasopressin, firstly described in the late sixties [1]. In contrast to vasopressin, which binds to the different vasopressin receptors, DDAVP is a selective agonist for the V2 cell membrane receptor [2]. This vasopressin receptor subtype is expressed in the kidney-collecting duct, mediating the antidiuretic action, and is also present in endothelial cells, mediating most of the non-renal effects of DDAVP, including a potent hemostatic effect $[3,4]$.

In the middle nineties it was postulated that vasopressin gene-related expression is a feature of all breast cancers, and products of this expression are attractive as potential targets for therapy [5]. The presence of vasopressin receptors was documented in various human cancer cell lines [6], including breast cancer [7]. DDAVP exhibited modest but significant antiproliferative effects on MCF-7 and Skbr3 V2 receptor-expressing human breast carcinoma cell lines [8]. Such action was clearly mediated through agonist V2 receptor signaling, and thus involved activation of adenylate cyclase followed by intracellular cAMP elevation. The cytostatic effect could be blocked by the selective V2 receptor antagonist satavaptan (SR121463) [8]. It was also reported that the natural hormone 
vasopressin inhibited the in vitro growth of MCF-7 human breast carcinoma cells at high concentrations [9].

In 1999, we communicated for the first time that intravenous infusion of DDAVP can inhibit the development of metastasis in syngeneic Balb/c mice. At clinically relevant doses, the peptide inhibited by $70 \%$ experimental lung colonization of aggressive F3II mammary cancer cells [10], and dramatically decreased axillary lymph node metastasis in a mouse model of breast tumor manipulation and surgical excision [11]. Considering the antimetastatic properties of DDAVP as well as its well-known hemostatic effect and tolerability, we conducted a pilot veterinary clinical trial in dogs with locally advanced mammary cancer [12]. Perioperative administration of DDAVP at high doses of $1 \mu \mathrm{g} / \mathrm{kg}$ significantly prolonged disease-free and overall survival. An extended trial recently confirmed these results, showing a reduced incidence of local relapses and lung metastasis in treated animals, and a particular survival benefit in cases with more aggressive carcinoma [13]. It is likely that DDAVP infusion not only inhibits perioperative metastatic events, but also combats micrometastases that occur before surgery.

We have also explored the antitumor effects of DDAVP in combination with chemotherapeutic agents using the F3II mammary carcinoma. Weekly cycles of intravenous DDAVP contributed to impair aggressiveness of residual mammary tumors during chemotherapy [14]. Although preliminary, these preclinical results support the notion that DDAVP complements conventional cytotoxic drugs, and suggest the compound may affect the interaction of tumor cells with tissue microenvironment, modulating tumorinduced angiogenesis $[14,15]$. The dependence of solid tumors on angiogenesis for sustained growth and metastasis formation is an established concept in tumor biology, with well-documented therapeutic value [16]. Since the pioneering work of Folkman [17], a number of antivascular approaches have been described. The interest in angiogenesis inhibitors has been boosted by the finding of tumor-derived angiostatic agents, such as a fragment of plasminogen known as angiostatin [18]. Components of the plasminogen-activator system, including the serine proteases urokinase-type (uPA) and tissue-type (tPA), are involved in the proteolytic conversion of plasminogen to angiostatin in vitro, although the in vivo processes are not fully understood $[19,20]$. Complete and reproducible inhibition of angiostatin formation by cell lines secreting uPA and/or tPA was observed with specific serine protease inhibitors [19].

The aim of the present work was to explore the effects of DDAVP on tumor angiogenesis using the aggressive F3II mammary carcinoma in syngeneic mice. Intravenous administration of the compound markedly decreased vascularization of growing subcutaneous tumors, as well as inhibited the early angiogenic response around intradermal tumor inoculation sites. Additional in vitro studies, also performed in human breast carcinoma and microvascular endothelial cell lines, indicated that the anti-angiogenic effect of DDAVP may be associated with the generation of angiostatin by tumor cells.

\section{Materials and methods}

Cell lines and culture conditions

The mammary carcinoma cell line F3II is a highly invasive and metastatic variant derived from a clone of a spontaneous Balb/c mouse mammary tumor [10]. F3II cells were maintained in Dulbecco's modified Eagle's medium (DMEM, Gibco, Grand Island, New York, USA) supplemented with $5 \%$ fetal bovine serum (FBS), $2 \mathrm{mM}$ glutamine and $80 \mu \mathrm{g} / \mathrm{ml}$ gentamycin in monolayer culture, at $37{ }^{\circ} \mathrm{C}$ in a humidified atmosphere of $5 \% \mathrm{CO}_{2}$. The human breast carcinoma cell line MCF-7 was routinely grown in DMEM plus $10 \%$ FBS. Human microvascular endothelial cells (HMVEC) isolated from the human lung were obtained from Lonza (Walkersville, MD, USA). The cell line was cultured using complete endothelial cell basal medium-2 with specific growth factors (EGM-2 MV Bullet Kit, Lonza) and routinely cultured for up to 10 in vitro passages.

\section{Animals}

Pathogen-free female Balb/c mice were obtained from the School of Veterinary of La Plata National University (UNLP, La Plata, Argentina) and kept at our animal house facility according to an institutionally approved animal protocol. Food and water were provided ad libitum, and general health status of the animals was monitored daily. Animals with an age of 8-14 weeks and an average weight of $25 \mathrm{~g}$ were used.

\section{In vivo studies}

On day 0 , groups of at least five mice received $2 \times 10^{5}$ viable F3II cells in the subcutis of the right flank. The time of appearance of local tumors was monitored by palpation and further confirmed by histopathology. In all cases, tumors were diagnosed as spindle-cell carcinomas, as expected [11]. Tumor size was measured periodically with a caliper and tumor volume was calculated by the formula: $\pi / 6 \times$ width $^{2} \times$ length. Animals were sacrificed by cervical dislocation and necropsied on day 60. To examine tumor vascularization, tumors were removed, fixed with formalin and routinely processed for hematoxylin-eosin 
(H\&E) staining. The presence of blood vessels was confirmed with CD31 immunohistochemistry.

Treatment with DDAVP from Ferring Pharmaceuticals (Malmö, Sweden) was started after tumor formation at day 15. The compound was administered at a dosage within the range that other authors have previously used and proved enhanced antidiuretic and hemostatic effects $(0.3-2 \mu \mathrm{g} / \mathrm{kg})$. These doses are clinically relevant and have the advantage of being well characterized from a pharmacological point of view [3]. Since DDAVP showed tachyphylaxis with repeated daily applications [4], doses were administered on a weekly or thrice weekly basis. Mice were administered intravenously with weekly cycles of DDAVP at a dose of $2 \mu \mathrm{g} / \mathrm{kg}$ of body weight or thrice weekly at $0.3 \mu \mathrm{g} / \mathrm{kg}$. Control animals received only saline vehicle.

Complementary, we performed an intradermal angiogenesis assay, as a rapid and quantitative alternative to test DDAVP effects on tumor-induced neovascularization. Mice were injected intradermally with F3II cells $\left(2 \times 10^{5}\right.$ F3II cells in $0.1 \mathrm{ml}$ of DMEM plus trypan blue). Each mouse received two injections midlaterally in the thoracolumbar position of the trunk. After 4 days, animals were sacrificed and the skin was examined under a dissecting microscope. Quantification of vascularization was done by measuring the vessel density around each inoculation site. Daily intravenous doses of DDAVP $(2 \mu \mathrm{g} / \mathrm{kg})$ were administered throughout the experiment.

In vitro growth assays

In vitro experiments were performed using nanomolar and low micromolar concentrations of DDAVP, a range consistent with the in vivo dosage $[10,14]$. To assess the antiproliferative effect of DDAVP against rapidly growing tumor cells, a range of concentrations from $100 \mathrm{nM}$ to $1 \mu \mathrm{M}$ was used with a 3-day exposure of log-phase growing cells. F3II cells were seeded on 96-well plates $\left(2.5 \times 10^{3}\right.$ cells/well $)$ in DMEM plus $5 \%$ FBS. After $24 \mathrm{~h}$, the compound was added, culture was continued for $72 \mathrm{~h}$ and then tested by the MTT assay. Additionally, cytostatic effects of DDAVP were examined at low cell density by colony formation assay. F3II cells were plated at 300 cells $/ \mathrm{cm}^{2}\left(6 \times 10^{2}\right.$ cells/well in 24 -well plates $)$ and grown for 7 days in complete medium in the presence of proper concentrations of DDAVP. Cultures were then fixed with formalin, stained with crystal violet and colonies of $>50$ cells were counted. The concentration producing $50 \%$ inhibition (IC50) was determined by plotting the percentage of cell colonies versus drug concentration.

To evaluate direct effects of DDAVP on cultured microvascular endothelial cells a capillary tube morphogenesis assay was conducted. HMVEC cells were seeded on Matrigel coated wells $\left(2.5 \times 10^{4}\right.$ cells/well in 24 -well plates) and tube formation was assessed after $20 \mathrm{~h}$ in the presence of DDAVP (100 nM, $250 \mathrm{nM}$ and $1 \mu \mathrm{M})$. Capillary-like tube structures per field were quantified using an inverted microscope (magnification $\times 100)$.

\section{Antibodies}

An anti-vasopressin V2 receptor antibody produced in rabbit, recognizing a conserved human epitope of the receptor also expressed in mice and rats, was purchased from Santa Cruz Biotechnology Inc. (Santa Cruz, California, United States). A fluorescein (FITC)-conjugated goat anti-rabbit IgG (Chemicon International Inc., Temecula, CA, USA) was applied for immunofluorescence. Rabbit polyclonal antibodies against human plasminogen (Dako, Glostrup, Denmark), which recognize the kringle domains of angiostatin [19], and a goat anti-rabbit peroxidase-conjugated secondary antibody were used (Bio-Rad, Hercules, CA, USA).

Immunofluorescence detection of $\mathrm{V} 2$ vasopressin receptor

Cells were seeded on glass coverslips, washed with cold

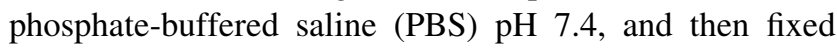
with $3 \%(\mathrm{w} / \mathrm{v})$ paraformaldehyde in PBS for $15 \mathrm{~min}$. Cells were washed with cold PBS, incubated with $50 \mathrm{mM}$ ammonium chloride for $5 \mathrm{~min}$, again washed with PBS, and incubated with $3 \% \mathrm{FBS}$ as blocking agent for $30 \mathrm{~min}$. Cells were then incubated with anti-V2 vasopressin receptor primary antibody $(4 \mu \mathrm{g} / \mathrm{ml}$ in $0.1 \% \mathrm{FBS})$ for $1 \mathrm{~h}$ at $37{ }^{\circ} \mathrm{C}$. Receptor-bound antibodies were detected with a secondary FITC-conjugated goat anti-rabbit IgG (1:400 in $0.1 \%$ FBS ) and nuclei were labeled with $4^{\prime}, 6$-diamidino-2phenylindole (DAPI) using the Vectashield fluorescent mounting medium (Vector Laboratories Inc., Burlingame, CA, USA). Samples were examined by standard fluorescence microscopy using a Nikon TE-2000 fluorescence microscope, and pictures were processed using Nikon NISElements software (Nikon, Tokyo, Japan). Cultures of MCF-7 human breast carcinoma cells were used as a positive control of $\mathrm{V} 2$ receptor expression, as reported [7]. Negative controls consisted of omission of the primary antibody and were consistently negative.

Digestion of plasminogen to angiostatin by cell-culture supernatant

From semiconfluent tumor cell cultures, serum-free conditioned medium was produced by washing the cells thrice with PBS, followed by overnight incubation with serumfree DMEM in the presence or absence of DDAVP. Conditioned medium was centrifuged to remove cell debris, 
and stored at $-20{ }^{\circ} \mathrm{C}$ until further use. Purified plasminogen from Chromogenix (Mölndal, Sweden) was added to conditioned media at a final concentration of $1 \mu \mathrm{g} / \mathrm{ml}$, and incubated at $37{ }^{\circ} \mathrm{C}$ for $24 \mathrm{~h}$ to allow angiostatin generation, as described previously [19].

\section{Zymography}

For detection of plasminogen activator forms contained in serum-free conditioned media, casein zymography was performed using SDS-polyacrylamide gel electrophoresis with $7.5 \%$ separating and $4 \%$ stacking gels. The separating gel was copolymerized with $12 \mu \mathrm{g} / \mathrm{ml}$ purified plasminogen and $5 \mathrm{mg} / \mathrm{ml}$ non-fat dried milk as casein source. After running, gels were washed with $2 \%$ Triton $\mathrm{X}-100$ and incubated at $37{ }^{\circ} \mathrm{C}$ for $24 \mathrm{~h}$ in $20 \mathrm{mM}$ Tris buffer (pH 8.3) containing $15 \mathrm{mM}$ EDTA. Upon staining with Coomassie blue and destaining, the final gel had a uniform blue background except in those regions to which proteases had migrated and activated plasminogen to plasmin. Molecular weights were determined by prestained standards (Bio-Rad, Hercules, CA, USA). Plasminogen-free gels were used to test plasminogen-independent protease activity. For evaluation of gelatinolytic metalloprotease (MMP) activity, zymographic analysis was performed using gels copolymerized with gelatin.

\section{Western blot}

For detection of plasminogen digestion and angiostatin generation, Western blot was performed essentially as described elsewhere [19]. Briefly, samples of conditioned medium incubated with plasminogen were run on a $7.5 \%$ polyacrylamide gel. After electrophoresis, samples were electroblotted onto polyvinylidene fluoride membranes. Blots were blocked for $60 \mathrm{~min}$ in blocking solution followed by overnight incubation with antibody diluted in blocking solution. After washing, blots were incubated for $1 \mathrm{~h}$ with peroxidase-conjugated secondary antibody. After washing, blots were developed by chemiluminescence according to the manufacturer's protocol (ECL, General Electrics, Fairfield, CT, USA). Angiostatin bands were further analyzed by densitometry using the Kodak Electrophoresis Documentation and Analysis System (EDAS 120) software (Kodak, Rochester, NY, USA), and expressed as fold change compared with untreated control cells.

\section{Statistical analysis}

Differences in in vitro and in vivo data between control and treated groups were evaluated with the GraphPad Prism 4.0 software package. $p$ values less than 0.05 were considered statistically significant.

\section{Results}

Reduction of tumor volume and angiogenesis by DDAVP administration in vivo

We first tested the effects of intravenous administration of DDAVP in Balb/c mice-bearing subcutaneous F3II mammary tumors. F3II cells grew as highly invasive carcinoma tumors in control animals. As shown in Fig. 1a, treatment of mice with a single weekly dose of $2 \mu \mathrm{g} / \mathrm{kg}$ significantly reduced tumor volume. A similar antitumor effect was obtained administering DDAVP thrice weekly at $0.3 \mu \mathrm{g} /$ $\mathrm{kg} / \mathrm{dose}(0.9 \mu \mathrm{g} / \mathrm{kg} /$ week $)$. No improved efficacy against mammary tumors was obtained with higher weekly doses of $6 \mu \mathrm{g} / \mathrm{kg}$ (data not shown). Histopathological studies performed on tumors treated with DDAVP showed a marked and statistically significant decrease in tumor vascularization (Fig. 1b, c).

We further evaluated the early angiogenic response by measuring the vessel density around intradermal tumor inoculation sites. F3II mammary tumor cells induced a prominent angiogenic response in control animals. Daily intravenous administration of DDAVP at a dose of $2 \mu \mathrm{g} / \mathrm{kg}$ significantly reduced tumor-induced angiogenesis (Fig. 2).

\section{In vitro cytostatic effect of DDAVP}

We next assessed the cytostatic effect of DDAVP on logphase growing F3II mammary carcinoma cells. After a 72-h exposure, DDAVP caused a modest but significant inhibition of cell growth, as reported previously for MCF-7 cells [8]. The higher dose of $1 \mu \mathrm{M}$ reduced proliferation in F3II monolayers up to $15-20 \%$ (Fig. 3a). On the other hand, DDAVP had a stronger effect on colony formation at low density, with an IC50 value of $700 \mathrm{nM}$ against F3II cells (Fig. 3b).

Expression of V2 vasopressin receptors in both tumor and endothelial cells

In order to check the expression of the V2 vasopressin receptor for which DDAVP is the selective agonist, an immunofluorescence assay was conducted. As shown in Fig. 4, F3II mouse mammary tumor cells brightly expressed the $\mathrm{V} 2$ receptor on the cell surface in a similar pattern than MCF-7, a human breast carcinoma cell line known to display normal forms of all vasopressin membrane receptors plus an abnormal V2 receptor [7]. HMVEC microvascular endothelial cells were also positive for the V2 


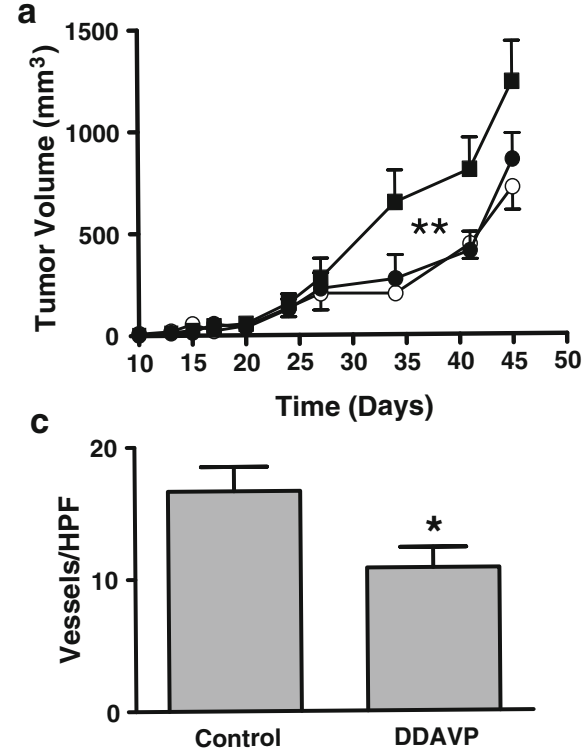

Fig. 1 Antitumor effects of DDAVP in syngeneic mice-bearing F3II mammary tumors. Animals were injected in the subcutis with $2 \times 10^{5}$ F3II cells, and intravenously administered with DDAVP or saline as a control. a Tumor growth curves of control (closed square) and treated animals, receiving weekly DDAVP at $2 \mu \mathrm{g} / \mathrm{kg}$ (closed circles) or thrice weekly DDAVP at $0.3 \mu \mathrm{g} / \mathrm{kg}$ (open circles). Data represent mean \pm standard error. Results are representative of three independent experiments. $* * p<0.01$ versus control, ANOVA plus Dunnett's test comparing the mean slopes from day 15 .

receptor (see also Fig. 4), as documented previously by RT-PCR [21].

Lack of direct effects of DDAVP on endothelial cells in vitro

Considering the anti-angiogenic effects observed in vivo, we first investigated direct effects of DDAVP on cultured microvascular endothelial cells. Endothelial tube formation in HMVEC cultures on Matrigel was not significantly affected by DDAVP at concentrations consistent with previous in vivo and in vitro studies, in a range from $100 \mathrm{nM}$ to $1 \mu \mathrm{M}$ (Table 1). Representative micrographs of capillarylike structures are depicted in Fig. 5.

Modulation of tumor-derived proteolytic activity by DDAVP and angiostatin formation

We then explored the proteolytic production of angiostatin by mammary tumor cells. In initial experiments, purified plasminogen was incubated with serum-free conditioned media from F3II monolayers for different period of times, and reaction products were analyzed by Western blot. After at least $20-24 \mathrm{~h}$, prominent bands of about 66 and 38-44 kDa corresponding to plasmin heavy-chain and angiostatin, respectively, were detected. Interestingly, b Representative micrographs of tumors from controls and mice treated with weekly DDAVP $(2 \mu \mathrm{g} / \mathrm{kg})$. Areas showing intratumoral and peritumoral vascularization are depicted. $H \& E$ staining, original magnification $\times 100$ (insets $\times 400$ ). c Quantitative analysis of intratumoral vascularization in controls and mice treated with weekly DDAVP $(2 \mu \mathrm{g} / \mathrm{kg})$. Blood vessels per high power field $(\mathrm{HPF}, \times 400)$ are shown. Data represent mean \pm standard error. ${ }^{*} p<0.05$, unpaired $t$ test

conditioned media from F3II monolayers cultured in the presence of low, non-cytostatic doses of DDAVP (100 nM) significantly increased angiostatin formation (Fig. 6a). Such increase was associated with an enhancement of tumor-secreted uPA activity $(50 \mathrm{kDa})$ in conditioned media containing purified plasminogen, as revealed by zymography (Fig. 6b). F3II monolayers also secreted a $105 \mathrm{kDa}$ protein with gelatinolytic activity, corresponding to MMP9. Although DDAVP induced a slight increase of this band, no clear dose-dependent effects were observed (data not shown).

Control MCF-7 human breast carcinoma cells were not able to excise angiostatin from plasminogen under the same experimental conditions, as previously reported [19]. However, treatment of MCF-7 monolayers with DDAVP gave rise to a detectable band of angiostatin (Fig. 6c).

\section{Discussion}

DDAVP is known to inhibit development of metastasis and contribute to impair aggressiveness of residual tumors during chemotherapy in the aggressive F3II mouse mammary cancer model $[10,11,14]$. To the best of our knowledge, this is the first study to examine the association between antitumor properties of a vasopressin peptide 

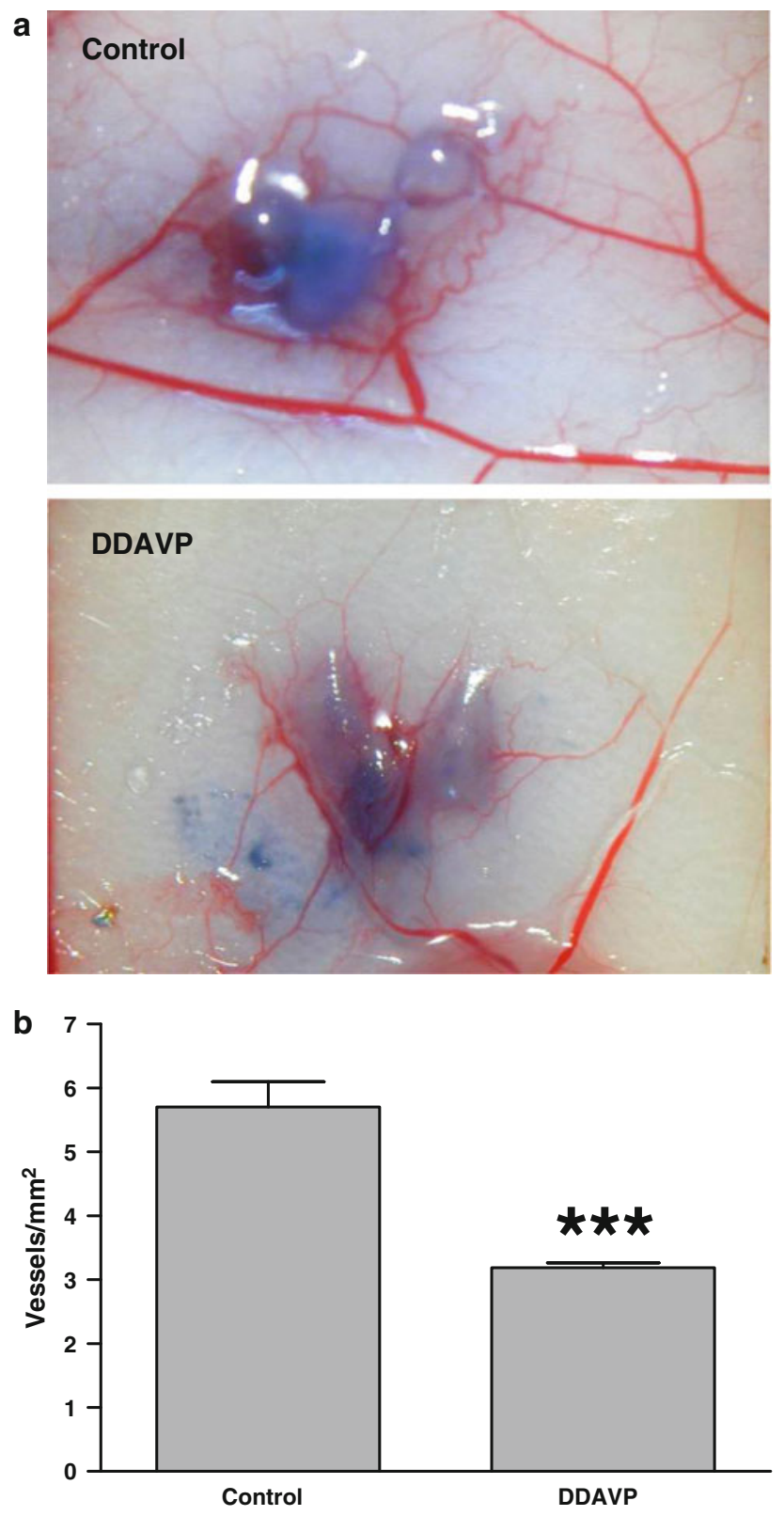

Fig. 2 Effect of DDAVP on the intradermal angiogenic response induced by F3II mammary tumor cells. Mice were inoculated intradermally with $2 \times 10^{5} \mathrm{~F} 3 \mathrm{II}$ cells, and intravenously administered daily with DDAVP at $2 \mu \mathrm{g} / \mathrm{kg}$ or saline as a control. a Representative micrographs of tumor inoculation sites from control and DDAVPtreated mice. Original magnification $\times 20$. b Quantitative analysis of angiogenic response. Data represent mean \pm standard error. Results are representative of three independent experiments. ${ }^{* * *} p<0.001$, unpaired $t$ test

analog and its potential angiostatic effect. Intravenous administration of DDAVP at clinically relevant doses of $0.3-2 \mu \mathrm{g} / \mathrm{kg}$ significantly decreased intratumor vascularization in mice bearing subcutaneous-growing F3II tumors. Similarly, treatment inhibited the early angiogenic
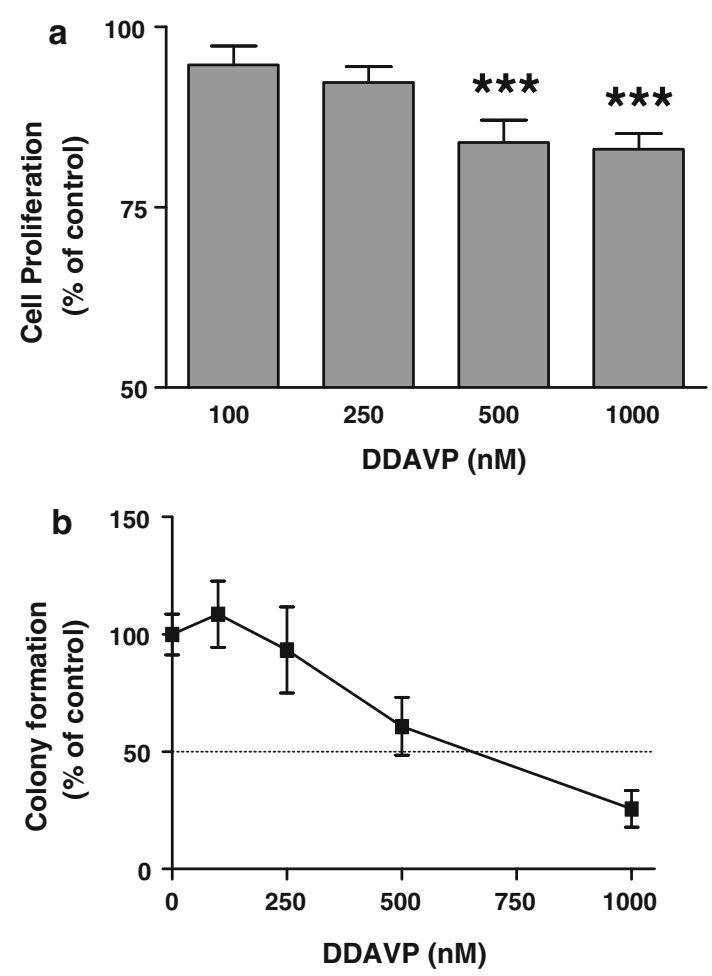

Fig. 3 Cytostatic effect of DDAVP on F3II mammary tumor cells. a 3-day exposure on log-phase growing cells using the MTT assay. $* * * p<0.001$ versus control, ANOVA plus Dunnett's test. b 7-day treatment on the colony formation assay at low density. Dotted line indicates the IC50 value $(700 \mathrm{nM})$. Data represent mean \pm standard error. In both cases, results are representative of at least three independent experiments

response by about $50 \%$ in the dermis around F3II cell inoculation sites.

Our findings suggested that DDAVP reduces tumor angiogenesis by inducing the formation of angiostatin, a potent naturally occurring inhibitor of angiogenesis that is generated by cancer-mediated proteolysis of plasminogen. A number of proteases can generate angiostatin, including MMPs and serine proteases [18-20]. DDAVP seemed to stimulate the secretion of plasminogen activators such as uPA by mammary tumor cells, thus excising angiostatin from plasminogen by controlled proteolysis. The involvement of plasminogen activators in angiostatin production has been convincingly demonstrated more than a decade ago by Gately et al. [22]. Plasmin generated by uPA is able to digest either plasmin itself or intact plasminogen thus leading to angiostatin formation. In human prostate and bladder carcinoma cell lines, a robust correlation of angiostatin with uPA levels, and in melanoma with tPA levels, was documented by Westphal et al. [19]. Conversely, cells lines that were unable to produce significant amounts of angiostatin, such as the MCF-7 human breast carcinoma, have very low or absent uPA and tPA levels [19]. 

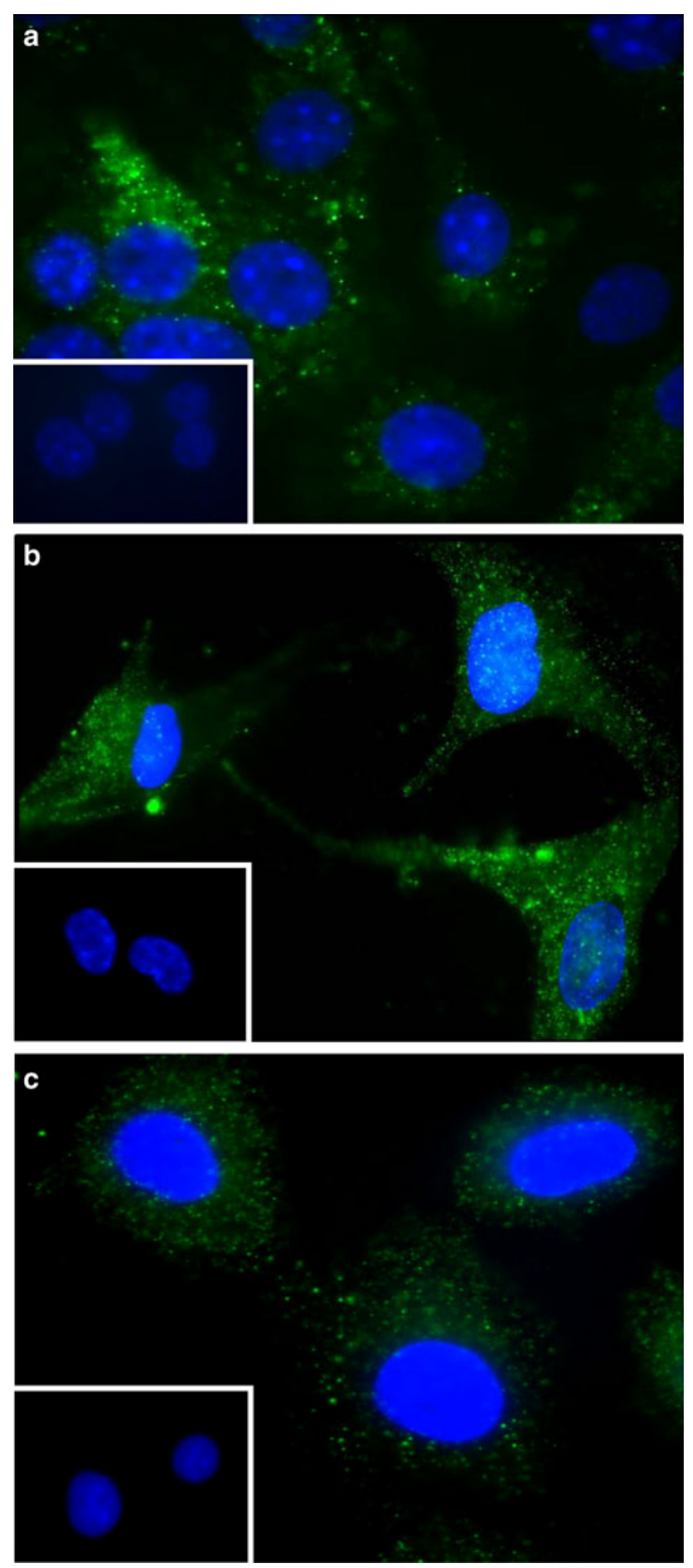

Fig. 4 Immunofluorescence detection of vasopressin receptor in tumor and endothelial cells. Vasopressin V2 receptor expression was detected using a specific anti-V2 antibody and a secondary antibody labeled with FITC. a F3II mouse mammary tumor cells. b HMVEC human microvascular endothelial cells. c MCF-7 human breast carcinoma cells (positive control). Insets, omission of the primary antibody (negative control). Original magnification $\times 1,000$
Table 1 Quantification of capillary-like tube structures in HMVEC cells after treatment with DDAVP

\begin{tabular}{lc}
\hline Treatment $^{\mathrm{a}}$ & Tube formation per field $^{\mathrm{b}}$ \\
\hline Control & $12.4 \pm 2.9$ \\
DDAVP 100 nM & $11.9 \pm 3.2$ \\
DDAVP 250 nM & $9.6 \pm 3.4$ \\
DDAVP 1,000 nM & $11.7 \pm 3.1$ \\
\hline
\end{tabular}

Non-significant differences among groups $(p>0.05$, ANOVA plus Tukey multiple comparison test)

${ }^{a}$ HMVEC cells were seeded on Matrigel, and tube formation was assessed after $20 \mathrm{~h}$ in the presence or absence of DDAVP

b Data are expressed as mean \pm standard deviation

DDAVP is likely to favor the production of angiostatin by experimental tumors in vivo, with consequent antiangiogenic effect. In mice bearing experimental tumors, angiostatin and the collagen-XVIII fragment endostatin were able to inhibit the growth, and even reduce the volume, of established disease [23]. Moreover, these experiments showed that anti-angiogenic therapy was not associated with acquired drug resistance [23, 24].

We cannot rule out the possibility that other underlying mechanisms account for the antitumor activity of DDAVP. In fact, the compound has a direct cytostatic effect on F3II cells and human breast cancer cell lines [8]. In addition, DDAVP induces a rapid increase in circulating von Willebrand factor (vWF) by stimulating its release mainly from microvascular endothelial cells through a specific agonistic action on V2 vasopressin receptors [25]. Interestingly, it was reported that inhibition of vWF expression by short interfering RNA in endothelial cells caused an increase of in vitro angiogenesis and vascular endothelial growth factordependent proliferation and migration [26], suggesting a potential role for $\mathrm{vWF}$ in the modulation of angiogenesis.

Breast cancer is one of the most commonly diagnosed malignancies in women and mortality due to the disease is related to the capacity of breast tumor cells to find alternative routes to vascularization and metastasis. A multidisciplinary approach to the management of breast cancer and the introduction of novel systemic therapies have improved the quality of life and survival of patients. In this regard, the potential combination of standard treatment with novel biological agents is exciting. Perhaps the greatest obstacle for therapy of an advanced cancer is that the outcome of residual metastasis depends on interactions of disseminated cells with homeostatic mechanisms which the tumor cells usurp. DDAVP appears as a safe agent to develop strategies for a pharmacological modulation of 

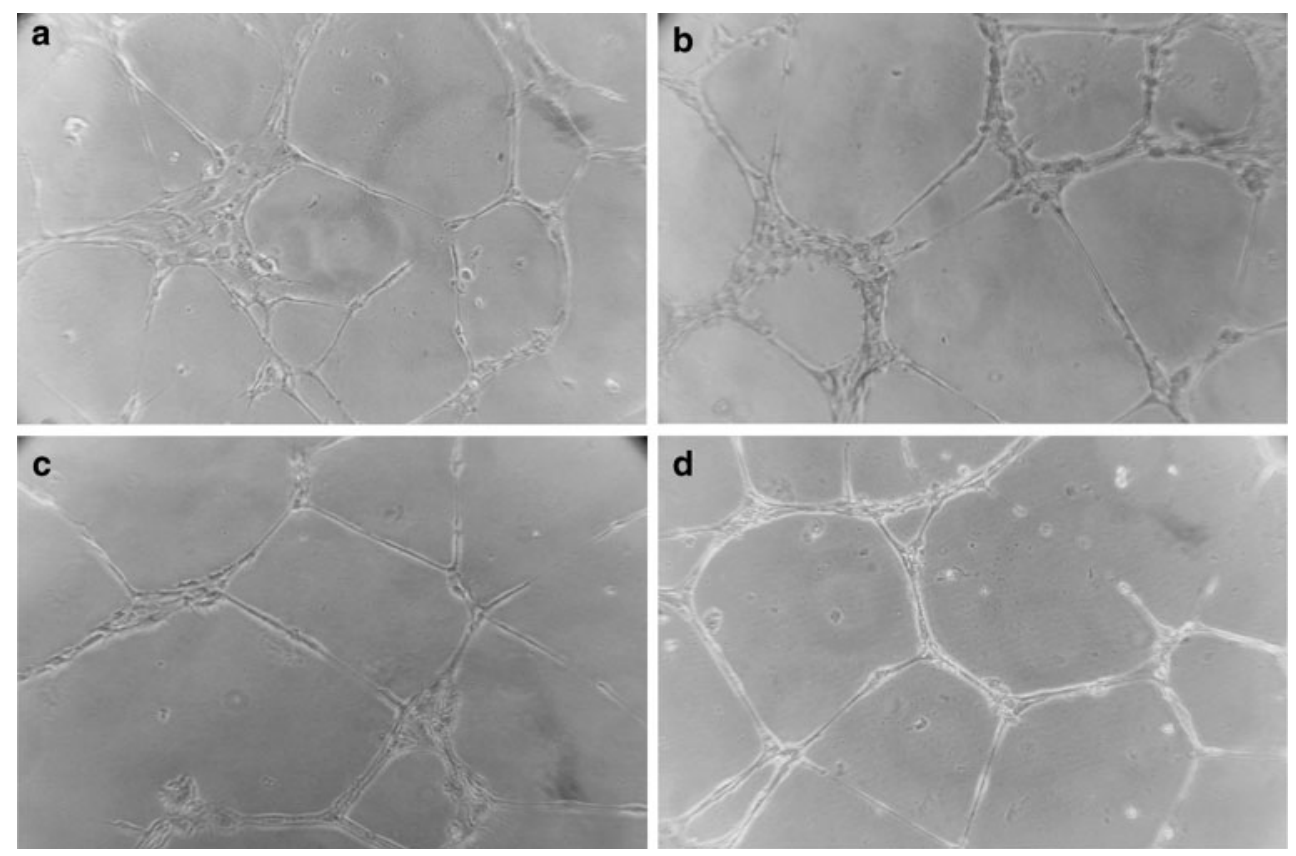

Fig. 5 Lack of effects of DDAVP on endothelial tube formation by HMVEC cells on Matrigel. Tube formation was assessed after $20 \mathrm{~h}$ in the presence or absence of DDAVP. a Control; b $100 \mathrm{nM}$; $250 \mathrm{nM}$;

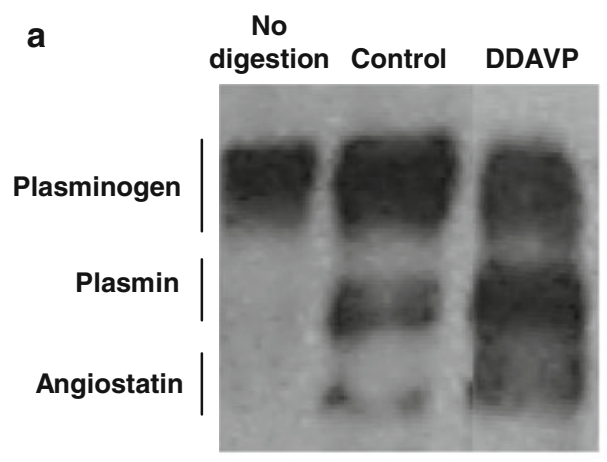

d $1 \mu \mathrm{M}$. The micrographs were taken with an inverted microscope. Original magnification $\times 100$

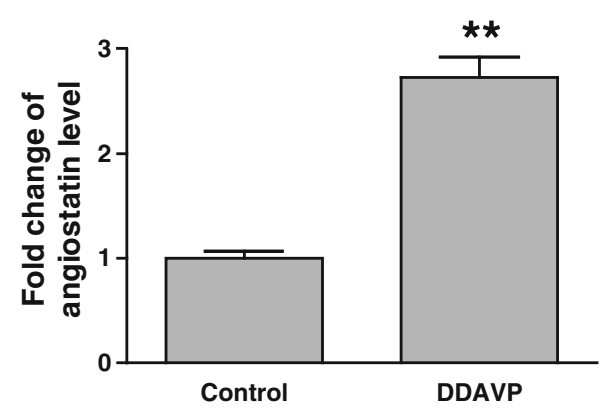

b

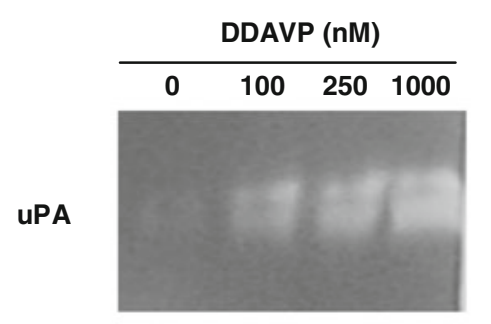

Fig. 6 Effect of DDAVP on angiostatin formation and tumor-derived proteolytic activity. a Western blot analysis (left) of protein fragments generated by digestion of purified plasminogen by serum-free conditioned media from F3II mouse mammary tumor cells cultured with or without DDAVP $(100 \mathrm{nM})$. Bands obtained at time 0 (no digestion of plasminogen) and after $20 \mathrm{~h}$ of digestion are shown. Quantitative analysis (right) of angiostatin band (38-44 $\mathrm{kDa}$ ) by densitometry is also shown. Data represent mean \pm standard error.
C

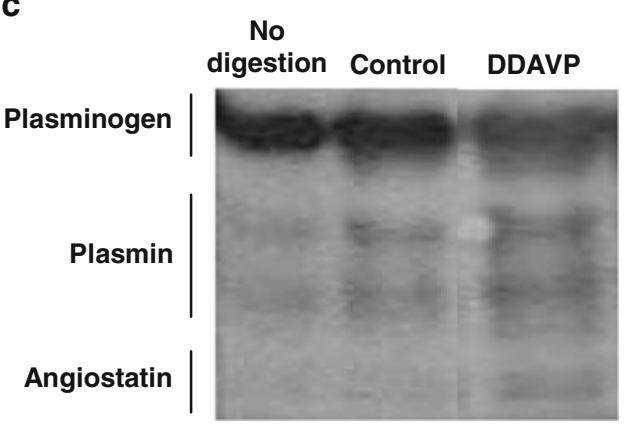

Results are representative of three independent experiments. $* * p<0.01, t$ test. b Zymographic analysis of uPA (50 kDa) secreted by F3II monolayers to the conditioned media after exposure to varying concentrations of DDAVP. c Angiostatin formation by medium conditioned by MCF-7 human breast carcinoma cells treated with DDAVP (100 nM). Molecular weights were determined using pre-stained standards 
angiostatin production and tumor-endothelial interactions [15]. Synthetic peptides such as DDAVP are much appreciated as lead compounds for developing human therapeutics, having a great potential as therapeutic agents due to their ease of rational design and target specificity [27]. Currently, a panel of linear and cyclic vasopressin peptide analogs with improved antitumor effects is in development in our laboratory. Punctual amino acid substitutions in DDAVP generate novel synthetic oligopeptides with enhanced cytostatic or anti-angiogenic effects [28]. However, the effects of such novel compounds on the release, by endothelial cells, of vWF and other hemostatic factors such as factor VIII remained to be investigated. We consider that further preclinical studies with DDAVP, as well as with derivatized analogs, are warranted to determine their potential utility in cancer therapy.

Acknowledgments We would like to thank Dr. Alejandra Scursoni for expert histopathological assessment. J.G. is a research fellow and G.V.R., H.G.F, D.E.G. and D.F.A. are members of the National Research Council (CONICET, Argentina).

Conflict of interest This work was partially funded by the National Agency for the Promotion of Science and Technology (ANPCYT, Argentina) and Chemo-Romikin. The authors have no other relevant affiliations or financial involvement with any organization or entity with a financial interest in or financial conflict with the subject matter or materials discussed in the manuscript apart from those disclosed.

Open Access This article is distributed under the terms of the Creative Commons Attribution Noncommercial License which permits any noncommercial use, distribution, and reproduction in any medium, provided the original author(s) and the source are credited.

\section{References}

1. Zaoral M, Kole J, Sorm F (1967) Synthesis of 1-deamino-8-Damino-butyrine vasopressin, 1-deamino-8-D-lysine vasopressin and 1-deamino-8-D-arginine vasopressin. Collect Czechoslov Chem Commun 32:1250-1257

2. Birnbaumer M (2000) Vasopressin receptors. Trends Endocrinol Metab 11:406-410

3. Mannucci PM (1997) Desmopressin (DDAVP) in the treatment of bleeding disorders: the first 20 years. Blood 90:2515-2521

4. Kaufmann JE, Vischer UM (2003) Cellular mechanisms of the hemostatic effects of desmopressin (DDAVP). J Thromb Haemost 1:682-689

5. North WG, Pai S, Friedmann A, Yu X, Fay M, Memoli V (1995) Vasopressin gene related products are markers of human breast cancer. Breast Cancer Res Treat 34:229-235

6. Petit T, Davidson KK, Lawrence RA, von Hoff DD, Izbicka E (2001) Neuropeptide receptor status in human tumor cell lines. Anticancer Drugs 12:133-136

7. North WG, Fay MJ, Du J (1999) MCF-7 breast cancer cells express normal forms of all vasopressin receptors plus an abnormal V2R. Peptides 20:837-842
8. Keegan BP, Akerman BL, Pequeux C, North WG (2006) Provasopressin expression by breast cancer cells: implications for growth and novel treatment strategies. Breast Cancer Res Treat 95:265-277

9. Taylor AH, Ang VT, Jenkins J, Silverlights RC, Coombes RC, Luqmani YA (1990) Interaction of vasopressin and oxytocin with human breast carcinoma cells. Cancer Res 50:7882-7886

10. Alonso DF, Skilton G, Farias EF, de Kier Bal, Joffe E, Gomez DE (1999) Antimetastatic effect of desmopressin in a mouse mammary tumor model. Breast Cancer Res Treat 57:271-275

11. Giron S, Tejera AM, Ripoll GV, Gomez DE, Alonso DF (2002) Desmopressin inhibits lung and lymph node metastasis in a mouse mammary carcinoma model of surgical manipulation. J Surg Oncol 81:38-44

12. Hermo GA, Torres P, Ripoll GV, Scursoni AM, Gomez DE, Alonso DF, Gobello C (2008) Perioperative desmopressin prolongs survival in surgically treated bitches with mammary gland tumours: a pilot study. Vet J 178:103-108

13. Hermo GA, Turic E, Angelico D, Scursoni AM, Gomez DE, Gobello C, Alonso DF (2011) Effect of adjuvant perioperative desmopressin in locally-advanced canine mammary carcinoma and its relation to histological grade. J Am Anim Hosp Assoc 47:21-27

14. Ripoll GV, Giron S, Krzymuski MJ, Hermo GA, Gomez DE, Alonso DF (2008) Antitumor effects of desmopressin in combination with chemotherapeutic agents in a mouse model of breast cancer. Anticancer Res 28:2607-2612

15. Alonso DF, Ripoll GV, Garona J, Iannucci NB, Gomez DE (2011) Metastasis: recent discoveries and novel perioperative treatment strategies with particular interest in the hemostatic compound desmopressin. Curr Pharm Biotechnol 12:1974-1980

16. Wu JM, Staton CA (2012) Anti-angiogenic drug discovery: lessons from the past and thoughts for the future. Expert Opin Drug Discov 7:723-743

17. Folkman J (1971) Tumor angiogenesis: therapeutic implications. New Engl J Med 285:1182-1186

18. O'Reilly MS, Holmgren L, Shing Y, Chen C, Rosenthal RA, Moses M, Lane WS, Cao Y, Sage EH, Folkman J (1994) Angiostatin: a novel angiogenesis inhibitor that mediates the suppression of metastases by a Lewis lung carcinoma. Cell 79:315-328

19. Westphal JR, Van't Hullenaar R, Geurts-Moespot A, Sweep FC, Verheijen JH, Bussemakers MM, Askaa J, Clemmensen I, Eggermont AA, Ruiter DJ, De Waal RM (2000) Angiostatin generation by human tumor cell lines: involvement of plasminogen activators. Int J Cancer 15:760-767

20. Sakurai T, Kudo M (2011) Signaling pathways governing tumor angiogenesis. Oncology 81(Suppl 1):24-29

21. Kaufmann JE, Oksche A, Wollheim CB, Günther G, Rosenthal W, Vischer UM (2000) Vasopressin-induced von Willebrand factor secretion from endothelial cells involves V2 receptors and cAMP. J Clin Investig 106:107-116

22. Gately S, Twardowski P, Stack MS, Cundiff DL, Grella D, Castellino FJ, Enghild J, Kwaan HC, Lee F, Kramer RA, Volpert O, Bouck N, Soff GA (1997) The mechanism of cancer-mediated conversion of plasminogen to the angiogenesis inhibitor angiostatin. Proc Natl Acad Sci 94:10868-10872

23. Boehm T, Folkman J, Browder T, O’Reilly MS (1997) Antiangiogenic therapy of experimental cancer does not induce acquired drug resistance. Nature 390:404-407

24. Sim BK (1998) Angiostatin and endostatin: endothelial cellspecific endogenous inhibitors of angiogenesis and tumor growth. Angiogenesis 2:37-48

25. Kaufman JE, Vischer UM (2003) Cellular mechanisms of the hemostatic effects of desmopressin (DDAVP). J Thromb Haemost 1:682-689 
26. Starke RD, Ferraro F, Paschalaki KE, Dryden NH, McKinnon TA, Sutton RE, Payne EM, Haskard DO, Hughes AD, Cutler DF, Laffan MA, Randi AM (2011) Endothelial von Willebrand factor regulates angiogenesis. Blood 117:1071-1080

27. Zompra AA, Galanis AS, Werbitzky O, Albericio F (2009)

Manufacturing peptides as active pharmaceutical ingredients.

Future Med Chem 1:361-377
28. Iannucci NB, Ripoll GV, Garona J, Cascone O, Ciccia GN, Gomez DE, Alonso DF (2011) Antiproliferative effect of 1-deamino-8-D-arginine vasopressin analogs on human breast cancer cells. Future Med Chem 3:1987-1993 